\title{
Evaluate Stochastikon Magister by Questionnaire
}

\author{
doi:10.3991/ijet.v6i1.1492 \\ Xiaomin Zhai, Elart von Collani \\ Würzburg University, Würzburg, Germany
}

\begin{abstract}
This paper is the continuation of the work of articles "Strategies for Teaching a Novel Approach to Handling Uncertainty Scientifically via Internet", "A Graphical Tool for Visualizing Bernoulli Stochastics" and "Empirical Evaluation of Stochastikon Magister". In this paper we evaluate the usability and learnability of the virtual classroom - Stochastikon Magister by questionnaire. The result shows that more than $70 \%$ of the teacher candidates, who selected Magister E-Learning programme to learn Bernoulli Stochastics, feel satisfactory with both Magister learning environment and Bernoulli Stochastics teaching content. Besides, most of the participants hold positive attitudes toward the possibility of using E-Learning systems as a replacement of classroom teaching for educating other subjects of mathematics and natural science. The response to the questionnaire is identical with another empirical evaluation of Stochastikon Magister.
\end{abstract}

Index Terms- Evaluation, Bernoulli Stochastics, Online Education, Virtual Classroom, Questionnaire, Stochastic Procedures.

\section{INTRODUCTION}

The comparison of the examination scores of the teacher candidates, who took part in the course of Bernoulli Stochastics based on the E-Learning programme Stochastikon Magister on the one hand and in a course of traditional stochastics based on classroom teaching on the other reveals that the scores are quite similar [10]. The result therefore indicates the same degree and in some case even better of learnability for the two teaching alternatives.

However, this result may be argued because of the following reasons:

(1) Oral examinations are rather subjective and may not reflect objectively the learnability of the two teaching alternatives.

(2) Bernoulli Stochastics may be easier to learn than traditional stochastics and the scores reflect more the different contents than the different teaching methods.

(3) The students did learn Bernoulli Stochastics not primarily with Stochastikon Magister but from examination protocols of other students, from the literature, in groups, etc.

(4) The students can choose between Bernoulli Stochastics and traditional stochastics. Maybe the better students did choose Bernoulli Stochastics and the good scores are not due to Magister.

Any examination is to a certain degree subjective, but in this case subjectivity is reduced by the fact that there are two examiners, one professor (von Collani or Marohn) and one school teacher, and the school teachers are not only observers but also examiners, who must pose questions. Furthermore, the school teachers were partly the same persons for both the examinations in Bernoulli Stochastics and traditional stochastics. As already mentioned above it is therefore assumed here that a possible subjectivity of the examiners does not essentially affect the scores.

In order to check the validity of the other arguments a questionnaire was prepared and the participants in the examination in Bernoulli Stochastics were asked to answer it. The aim of the questionnaire is to assess the usability and learnability of Magister compared with classroom teaching from the students' point of view. The questionnaire designed for the evaluation of Stochastikon Magister has taken into account the relevant ISO standard cited below.

According to the "Guidance on Usability" [2]

\subsection{Usability measures}

\subsubsection{Choice of measures}

A description of usability measures consists of target or actual values of effectiveness, efficiency, and satisfaction for the required contexts. It is normally necessary to provide at least one measure for each of effectiveness, efficiency and satisfaction. Because the relative importance of components of usability depends on the context of use and the purposes for which usability is being described, there is no general rule for how measures should be chosen or combined.......

\subsubsection{Effectiveness}

Measures of effectiveness relate the goals or sub-goals of the user to the accuracy and completeness with which these goals can be achieved.......

\subsubsection{Efficiency}

Measures of efficiency relate the level of effectiveness achieved to the expenditure of resources. ......

\subsubsection{Satisfaction}

Measures of satisfaction describe the comfort and acceptability of the use.......

The invitation to participate the questionnaire was sent by email to 46 teacher candidates, who had taken part in the oral examination in Bernoulli Stochastics. The questionnaire was available online, and the time to complete the questionnaire lasted from $16^{\text {th }}$ February 2010 to $21^{\text {st }}$ March 2010. During this time period $31(67.4 \%)$ of the addressed students responded.

The evaluation of the examination scores was based on only 25 teacher candidates, namely those who took part in the examinations in 2007 and 2008. In contrast, the questionnaire was sent to all participants of the examinations in Bernoulli Stochastics, who were accessible by email connections. 
The questionnaire aims at evaluating Stochastikon Magister in particular and E-Learning in general with respect to the following points:

(1) The reasons for selecting Bernoulli Stochastics instead of traditional stochastics.

(2) The quality of teaching materials and learning environment of Magister.

(3) The technical design and implementation of Magister system.

(4) The comparison between Magister based E-Leaning and regular classroom teaching.

(5) The usability and learnability of E-Learning system like Magister for other subjects of mathematics and natural science.

In the remainder, traditional stochastics ${ }^{1}$ is named "statistics", and Bernoulli Stochastics is named "Stochastics". Moreover, "Question" is abbreviated by "Q", for example, "Q3" means "Question 3", and "Q5.1" means "Question 5.1". The answers are specified by the corresponding number of the choice separated by a hyphen. For instance "Q2-2" stands for the second choice of Question 2, "Q6.5-1" means the first choice of Question 6.5, and "Q4-23" represents the second and the third choice of Question 4. The evaluation grades used in the questionnaire to Stochastikon Magister range from 1 to 5 and stand for "very good", "good", "satisfactory", "sufficient" and "poor".

Content of the questionnaire is listed in the Appendix.

\section{DISCUSSION AND CONCLUSION}

One aim of the evaluation is to examine whether the better coordination of content-environment, designimplementation and target-outcome of Magister are reflected in the responses to the questionnaire.

Another aim of the questionnaire was to verify the conclusions gained by the comparison between the examination scores obtained in statistics on the one hand and Stochastics on the other [10].

Finally, the questionnaire should help to answer the question to which extent E-Learning can be used as an efficient alternative to classroom teaching especially for newly emerging subjects that are based on mathematics and for which no adequately educated teachers and teaching material are available.

The questionnaire consists of six questions for assessing the usability, learnability and also the popularity of Magister in particular and E-Learning in general from the viewpoint of the learners. The different questions are not independent, but are closely related and can therefore also be used for checking the consistency of the responses. The sample size is rather small, therefore allows only rather imprecise statements. Nevertheless, the conclusions to be drawn from the empirical results shall be based if possible on stochastic procedures. However, the reliability

\footnotetext{
1 In Germany the words "stochastics" and "statistics" are often used alternatively. For avoiding confusion between Bernoulli Stochastics and traditional stochastics and in line with the international practice, in the following, we only use the word "statistics" when it refers to the traditional class room teaching for statistics / traditional stochastics. A detailed explanation about the differences between "Bernoulli Stochastics" and "statistics" is given in the "Empirical Evaluation of Stochastikon Magister" [10].
}

level will be selected as $\beta=0.80$, which is rather low but reasonable when taking into account the small sample size.

Very few students did not make choices to all questions of the questionnaire. In all only eleven (sub-) questions were not answered, which include two follow-up questions, which could not be answered reasonably by the related two participants. Furthermore, one student was accountable for five of the eleven unanswered questions. The high response rate $(98.13 \%)$ indicates that questions of the questionnaire are understandable and reasonable, and we conclude that the responses reflect without noteworthy bias the opinions of the participants. In the following, some points of interest with respect to the questionnaire are briefly treated.

\section{A. Selection Criteria}

The first issue that shall be examined refers to the reasons for selecting Stochastics instead of statistics. The responses show that the recommendations of fellow students represent the main reason for selecting Stochastics. We conclude that a majority of the students decided on learning Stochastics without having seriously engaged in Stochastics, while some few had a vague idea of some characteristic features of Stochastics. This means that the selection of Stochastics and the examination scores are more or less stochastically independent.

\section{B. Mode of Learning}

More than half of the students prepared their examination primarily on the basis of print-outs of the lessons, while one third of the students studied Stochastics online at home. One tenth of the students studied mainly in groups, and only one student stated that examination protocols of other students were his main learning materials. None of the students mentioned online learning in a CIP-pool. Note that the questionnaire allowed to specify only the most appropriate response, therefore someone, who learned primarily from print-outs or in groups, may have frequented Magister online as well.

The responses confirm that all participants have Magister experiences, as even the single student who learned mainly from former protocols, answered all questions about Magister in the questionnaire. The differences in the main learning methods refer to the intensity of using a PC and the Internet. The fact that none of the students mentioned learning in a CIP-pool and only one third learning on-line at home, while more than half of the students preferred to learn from print-outs might indicate that teacher candidates are less accustomed to use the Internet for learning and preparing. However, whether or not such a conjecture is correct, should be investigated separately.

Almost three quarters of the student state that they had no E-Learning experience except Magister. This might be an explanation to the above fact that nearly two third of the students did not select study online as their major learning method, but prefer to learn from printed media, as they were used during more than 15 years to classroom teaching and learning. This appears to be a reasonable behaviour since a completely new learning mode such as online learning may lead to frustration, confusion and difficulties. Some students may feel lost during preparation based on E-Learning because they miss the familiar classroom teaching. This effect could also be caused by the restrictions of the technical factors 
(equipment, environment, etc.) and the specific personal factors (learning habit, preference and (E-) learning experience).

The main complaint about the famous CyberStats system is, according to [4], the fact of "not having a printed version of the textbook" and the authors are pleased that "recently, a printed version of CyberStats has been made available upon request." In [5] it is stated that "Ideally an electronic textbook should be available in all three formats, i.e., CD, Web, and print..." Therefore, it is not surprising that $64.52 \%$ of student did not select online learning and half of the students accomplished their preparation mainly by means of the printed documents. Actually, the design of Magister had taken these situations into account by providing a convenient environment to handle these diversities [7].

\section{Appreciation of Magister Learning Environment}

The technical issue of the Magister virtual learning environment was assessed by the characteristics "ease of use", "clarity of lessons", "system response", "stability", "layout" and "satisfaction of working with Magister" in Q5. The overall assessment of technical quality of Magister with reliability level $80 \%$ yields a value between 1.41 and 2.56, which seems to be rather good.

Fig. 1 shows the ratio of positive responses to Magister. The diagram indicates that according to learners, Magister is well suited for learning Stochastics.

The positive responses to the questionnaire and the positive scores obtained in the Stochastics examination indicate not only a high degree of acceptance of Magister, but also that E-Learning can be a fully valid substitute for classroom teaching in Stochastics education. These results are in contrast to some experiences with E-Learning programs in mathematics and some doubts about ELearning [1]. The reasons for the observed difference may be manifold, but some points in favor of Magister can be conjectured as follows:

(1) Stochastics is a unified subject that is based on an unambiguously defined concept probability, on a clear model for uncertainty, and a methodology that is build up on prediction procedures. In contrast, statistics is a methodology that does not follow clear rules and moreover the concept probability has several inconsistent interpretations. The clarity of Stochastics on the one hand, and the blur of statistics on the other, facilitates teaching and learning of the former.

(2) In contrast to many E-Learning programs in statistics, Magister is designed to include a complete virtual

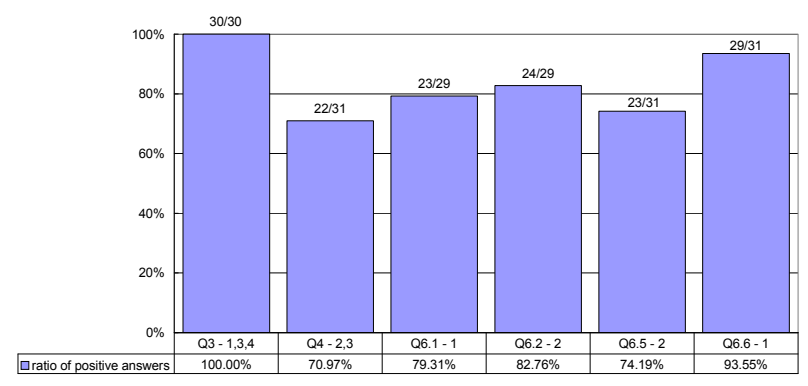

Figure 1. The ratio of positive answers in comprehensive questions about Magister system classroom environment, which in case of understanding problems offers at least as much support as a real classroom. The possibility to get help whenever it is necessary does probably also contribute to the acceptance of Magister.

(3) The fact that the development of content and technical issue of Magister lay in one hand has led to a more self-contained E-Learning system, which facilitates the control of quality of the whole project.

(4) Finally, in this evaluation, teacher candidates in mathematics are the target group of Magister. They have a rich mathematical background and enough self-study abilities. Therefore, if the learning environment is satisfactory, the learning support is strong and the learning material is sufficient, then achieving the learning goal in Stochastics should be not difficult for them, even in the case that the learning mode is completely new.

\section{Acceptance of E-Learning}

Magister offers E-Learning instead of classroom teaching for Stochastics, because there are no textbooks or trained teachers in Bernoulli Stochastics. Acceptance by the teacher candidates is one of the necessary conditions that Magister can meet its aim. The examination scores indicate that the aim is actually achieved [10]. The questionnaire should support this conclusion, by providing information about how the teacher candidates used Magister, which impression they got about Magister and how the quality of Magister is assessed by them. As being discussed in the "Appreciation of Magister Learning Environment" the questionnaire shows that almost all of the students accepted E-Learning by Magister and appreciate to work with Magister. Moreover, based on their Magister experiences almost all students agree that E-Learning could replace classroom teaching, and finally all of them passed the examination successfully.

The questionnaire also reveals relations between the selected learning mode and previous E-Learning experiences, the benefits obtained from Magister, the personal E-Learning experiences with Magister, and the quality of the Magister learning environment. To sum up, the responses to the questionnaire by the participants show that Magister was widely accepted as a substitute for classroom teaching in statistics.

\section{E. Consistency of Examination Scores and Questionnaire Responses}

The questionnaire about Magister reveals that there are two groups of students with rather different attitudes towards Magister and E-Learning. There is a larger group of about $70 \%-85 \%$ of the students, and a smaller group of the remaining students. This division can be observed from the responses to Q4 (helpfulness of Magister for exam preparation), Q6.1 (understanding difficulties with Stochastics in Magister), Q6.2 (solving comprehension problems in Magister) and Q6.5 (missing classroom teaching during exam preparation) (see Fig. 1).

Students in the larger group appreciate Magister by a much higher percentage of positive responses. They prefer E-Leaning for Stochastics to classroom teaching; they feel that Magister facilitates the exam preparation and consider that similar E-Learning systems as Magister would also be beneficial to other subjects; they met less comprehension 
difficulties with Stochastics by Magister than with statistics by classroom teaching; they seldom or never miss classroom teaching when learning in the new virtual environment; they overcome comprehension difficulties easier in Stochastics with Magister than in statistics by classroom environment, and they are confident that ELearning could be used successfully instead of classroom teaching for other mathematical and natural scientific subjects.

Students in the smaller group would like to have a regular course for Stochastics; they learned Stochastics mainly on the basis of print-outs or in groups, they experienced more problems and found that it was more difficult to overcome the problems in the Magister environment than in a classroom environment. Moreover, they missed classroom teaching during the exam preparation. Finally, their confidence in E-Learning and in Magister is less pronounced than that of the larger group.

Table I is taken from the "Empirical Evaluation of Stochastikon Magister" [10]. It displays the probability distributions (best cases and worst cases) for the students' scores in Wuerzburg examinations in Bernoulli Stochastics in the year 2007 and 2008 with reliability level of $\beta=0.80$, and specifies the probability of getting an honor result in the oral examination.

$X$ stands for the future examination score in Stochastics of a student with exam preparation based on Stochastikon Magister. Based on the score results $x$, the measurement result for the probability for an honor examination is given by the following interval:

$$
C^{(0.80)} P(x)=\{p \mid 0.71 \leq p \leq 0.90\}
$$

In order to compare the examination scores with the questionnaire responses we use the evaluation of the technical characteristics in Q5 to determine questionnaire scores about the Magister performance and compare them with the examination scores. Omitting the two questions referring to the Graphical Lab, there are six questions in Q5 with grades 1 to 5 . The sum of the grades in each questionnaire may vary between 6 and 30 , where 6 is achieved if each of the six characteristics is valued with the best grade 1, and 30 if each of the characteristics is valued with the worst grade 5. For defining an overall grade either the total sum of grades or the average grade is used as specified in Table II.

30 of the 31 participants valued all six technical characteristics and are therefore considered here. The last column in Table II displays the observed grade distribution by the questionnaire.

We define the grade "very good" and "good" as "honor

TABLE I.

Probability Distribution $P_{X_{3}}$ IN THE CASE OF WÜRZBURG EXAMINATIONS IN BERNOULLI STOCHASTICS:

\begin{tabular}{|c|l|l|}
\hline Grade & $\begin{array}{c}\text { worst case, i.e., largest } \\
E\left[X_{3}\right] \text { and } V\left[X_{3}\right]\end{array}$ & $\begin{array}{c}\text { best case, i.e., smallest } \\
E\left[X_{3}\right] \text { and } V\left[X_{3}\right]\end{array}$ \\
\hline 1 & 0.37428 & 0.53964 \\
2 & 0.33793 & 0.35956 \\
3 & 0.19549 & 0.091556 \\
4 & 0.072465 & 0.0089091 \\
5 & 0.017211 & 0.00033130 \\
6 & 0.0026191 & 0.0000047080 \\
\hline with honor & 0.71221 & 0.89920 \\
failed & 0.019830 & 0.00033601 \\
\hline
\end{tabular}

TABLE II.

OVERALL GRADES AND GRADE DISTRIBUTION OF THE MAGISTER TECHNICAL PERFORMANCE

\begin{tabular}{|l|c|c|c|}
\hline Overall grade & $\begin{array}{c}\text { Total sum } \\
\text { of scores }\end{array}$ & Average score & $\begin{array}{c}\text { Number of } \\
\text { students }\end{array}$ \\
\hline very good (1) & $6-8$ & $1.0-1.33$ & 4 \\
\hline good (2) & $9-14$ & $1.5-2.33$ & 21 \\
\hline satisfactory (3) & $15-20$ & $2.5-3.33$ & 5 \\
\hline sufficient (4) & $21-26$ & $3.5-4.33$ & 0 \\
\hline poor (5) & $27-30$ & $4.5-5.0$ & 0 \\
\hline
\end{tabular}

performance" of Magister and determine a measurement interval for the probability of an honor performance based on the questionnaire responses.

The sample size is $n=30$ and the number of the observed honor grades is $x=25$. The probability is determined with a stochastic measurement procedure with reliability level $\beta=0.80$. The measurement result for the probability of an honor result for the technical performance of Magister is given by the following interval:

$$
C^{(0.80)} P(25)=\{p \mid 0.70 \leq p \leq 0.89\}
$$

The conformance of the result with respect to the probability for an honor examination and the probability for an honor performance is striking. For both probabilities we obtain almost identical measurement intervals. This reflects the experience that students achieve good grades, if they are comfortable with the teaching method and environment.

In the following, we analyze the responses of Q6 by first defining a positive performance of Magister and then determine the probability for a positive evaluation by means of stochastic measurement procedures with reliability level $\beta=0.80$ based on the questionnaire results.

Responses to Q6.1-1 (understanding difficulties with Stochastics in Magister), Q6.2-2 (solving comprehension problems in Magister), Q6.5-2 (missing classroom teaching during exam preparation) and Q6.6-1 (e-learning for other scientific subjects) are looked upon as a positive performance. A "very good" performance is defined, if all four responses are positive; a "good" performance is defined by three positive responses, a "satisfactory" performance by two positive responses, a "poor" performance by one positive response, and finally a "very poor" performance by no positive response. Next, we define the grades "very good" and "good" as an honor performance and wish to determine the probability of such an honor evaluation. 28 of the 31 participants gave responses to all the four questions. In Table III the above grading system is given together with the questionnaire

TABLE III.

A SYNTHETIC ANALYSIS OF POSITIVE RESPONSES TO QUESTIONS IN Q6

\begin{tabular}{|l|c|c|}
\hline $\begin{array}{c}\text { Performance } \\
\text { Grade }\end{array}$ & $\begin{array}{c}\text { Number of positive } \\
\text { response }\end{array}$ & $\begin{array}{c}\text { Number of } \\
\text { student }\end{array}$ \\
\hline very good & 4 & 18 \\
\hline good & 3 & 6 \\
\hline satisfactory & 2 & 2 \\
\hline poor & 1 & 1 \\
\hline very poor & 0 & 1 \\
\hline
\end{tabular}


result.

In Table III the above grading system is given together with the questionnaire result.

The sample size is $n=28$ and there is a number of $x=$ 24 of honor grades. The honor probability is again determined with a stochastic measurement procedure based on a reliability level of $\beta=0.80$. The measurement result for the probability of an honor evaluation of Magister in particular and E-Learning in general is given by the following interval:

$$
C^{(0.80)} P(24)=\{p \mid 0.75 \leq p \leq 0.91\}
$$

In Fig. 2 the measurement intervals (reliability level $\beta=$ 0.80 ) for the probability of a positive evaluation of the various for the technical characteristics in Q5 and Q6 are displayed. Moreover, the honor evaluations for Q5, Q6 and students' score with honor in Stochastics as given above are also included in Fig. 2.

The measurement results of the probabilities of a positive evaluation are consistent with one another as the intervals overlap. One measurement result namely with respect to Q5.5 seems to be out of the ordinary. This question refers to the layout of Magister and we noted earlier that grading the layout is much more subjective than that of other technical characteristics.

The questionnaire was executed after the oral examinations and, therefore, the test scores may have had an influence on the students' responses. On the other hand, the students had got their scores when they took part in the questionnaire, and therefore it is to be expected that the participants express their opinions in the questionnaire more frankly and truly. Anyway, the consistency of the score evaluation with the results of the questionnaire supports the reasonability and reliability of both investigations on Magister.

\section{$F$. Influence of E-Learning Experiences}

We divide the participants in those with only little ELearning experience and those with more E-Learning experience. As an indicator for little experiences we take the responses Q4-1 (group 1) and Q6.5-1 (group 2) for none of the students in these two groups has other ELearning experience except Magister, while Q2-2 (group 3) and Q6.3-1 (group 4) serve as indicators for more experience with E-Learning.

Four groups are defined and opposed with a number of responses to investigate the effects of the degree of ELearning experience. The groups and the considered responses are given below:

- Q4-1: preference for regular course for Stochastics. (group 1 contains 7 students)

- Q6.5-1: miss classroom teaching during exam preparation. (group 2 contains 8 students)

- Q6.3-1: experience with other E-Learning systems besides Magister. (group 3 contains 8 students)

- Q2-2: preparation by online learning at home. (group 4 contains 11 students)

- Q2-3: preparation by print-out lessons.

- Q6.1-1: more comprehension difficulties with statistics and classroom teaching

- Q6.6-1: E-Learning system like Magister would also be successful for other subjects besides Stochastics.

Fig. 3 shows the very pronounced difference between the groups 1 and 2 on the one hand and groups 3 and 4 on the other. Actually the groups 3 and 4 are more or less identical except for one single student in group 4, who responded negatively to Q4, Q6.1, Q6.5 and Q6.6. This student also gave the lowest ratings to Q5. He had no previous E-Learning experience but selected nevertheless online learning at home. Maybe this was a wrong decision that may explain his negative responses that affect the values of group 4 by about $9 \%$. His responses may be looked upon as not reflecting the overall opinion of group 4 students on E-Learning in general and Magister in particular.

Having this in mind we conclude that the result of the questionnaire shows that previous E-Learning experiences as well as the amount of E-Learning practices have a positive impact on the results obtained by working with Magister and on the attitudes toward E-Learning.

Less than half of the students who selected online learning at home had previous E-Learning experiences and only $60 \%$ of the students with previous E-Learning experiences selected online learning at home. Thus, one may conclude that the relation between previous ELearning experiences and the selection of online learning is not really close. If this is correct then on-line learning may be much more related to technical factors (equipment, environment, etc.) and personal factors (habit, preference, etc.).

\section{G. Overall Performance Rating}

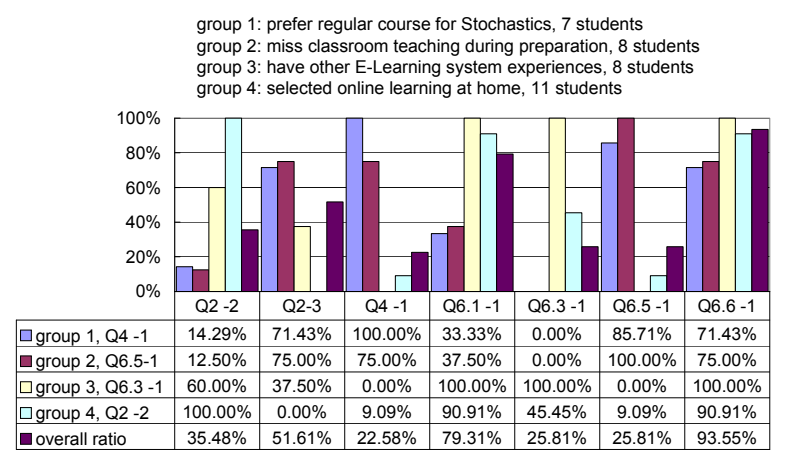

Figure 3. Comparison of choices between four groups of students 
For evaluating Magister the overall performance rating is of particular significance. Fig. 4 shows the overall performance rating with respect to Q5 for each response to Q2, Q3, Q4, and Q6, which was selected by more than one student independently whether the response was positive or negative. The bars representing average scores of negative responses are striped.

According to Fig. 4 positive responses to Q2, Q3, Q4 and Q6 lead without exception to a better overall rating of the performance characteristics included in Q5 than negative responses. This fact shows the consistency of the response. The result also indicates that the subjective evaluation of Magister depends likewise on the technical environment and the scientific content. As to the overall rating of the performance criteria of Magister (Q5), the worst average score is 2.33 given by those students who prepared for the examination in groups, those who feel that Magister was no help for the exam preparation, and those who are not in favour of E-Learning in other scientific subjects. For all positive responses the average scores for the performance characteristics (Q5) are better than 2 ("good").

\section{H. Special Performance Characteristics}

It is not surprising that the grades for the technical performance characteristics "ease of use", "system response", "stability" and "satisfaction of working with Magister" are positively correlated with one another and with positive responses in other questions.

In contrast, there seems to be no significant relations between the characteristic "clarity of the lessons" and other technical performance characteristics. However, "clarity of the lessons" seems to be closely related to the responses to the question whether Magister is a sufficient basis to understand the examination material (Q3).

Fig. 5 shows that $75 \%$ of the students, who valued the clarity of Magister lessons as being very good (group 1), consider Magister as a sufficient basis to understand the examination material. The remaining $25 \%$ think that it is sufficient but would appreciate more examples and exercises. One third of the students of group 2 (evaluated the clarity of Magister Lessons as "good") also consider the Magister lessons as being sufficient, another one third would appreciate more examples and exercises, while the remaining students think that a face-to-face introductory meeting is necessary. The situation in group 3 (thought the clarity of Magister lessons as "satisfactory") is different. None of the students considers the Magister lessons

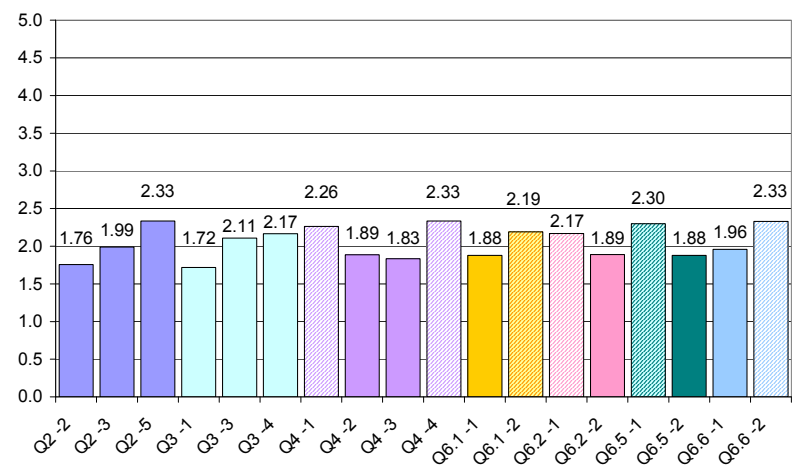

Figure 4. Overall ratings of Q5 given by different selections in other comprehensive questions of the Questionnaire

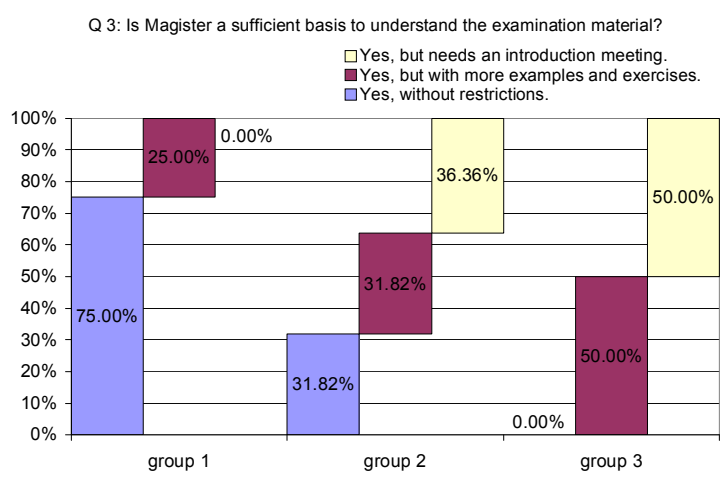

Figure 5. Relation between the clarity of Magister lessons and the sufficiency of Magister as a learning basis for Stochastics

without further support as being sufficient. 50\% of the students want additional examples and exercises and 50\% think that an introductory meeting is necessary.

These two aspects may therefore be used to assess the quality of the teaching content in Magister.

The characteristic "system layout" is also more or less independent of the other performance characteristics, although the questionnaire result indicates a positive correlation between "system layout" and "ease of use". Actually, "system layout" got the worst overall evaluation score (2.23) among all evaluated characteristics. The evaluation of the layout depends more than all other characteristics on individual aesthetics and preferences. However, the questionnaire shows that especially those students who worked with Magister online and who are therefore familiar with the system layout evaluated it best. Maybe the first impression about the layout is less good, but it gets better by working with it. This change might be caused if a user working online with Magister switches to the other components like Calculator, Encyclopedia, Mentor, etc. of the Stochastikon system and feels immediately familiar with them because they have the same layout as Magister [7].

\section{Graphical Laboratory}

There are two sub-questions included in the questionnaire concerning the Graphical Lab [8], one refers to the "frequency of using the Graphical Lab" (Q5.7), and the other refers to the "ease of using the Graphical Lab" (Q5.8). These questions were included to provide information about the interest of the students in Stochastics that exceeds the needs for passing the examination, since familiarity with the Graphical Lab is not a subject of examination.

The responses to these questions reveal that more than $80 \%$ of the students at least tried the Graphical Lab, and more than half of these students have worked with it at least occasionally.

Having in mind the rather limited impact of the Graphical Lab for the exam preparation, the overall evaluation of its "ease of use" (2.64) seems to be satisfactory.

The characteristic "ease of use" of Magister shows a positive correlation with both the frequency of using the Graphical Lab and the ease of use it. From this we conclude that ease of use of Magister may stimulate 
students' enthusiasm to try new and different functions and technical tools provided by Magister.

\section{J. Role of Magister and E-Learning}

The questionnaire shows that three-quarters of the teacher candidates have no other E-Learning experience except Magister. This fact seems to be surprising and it might indicate a shortcoming of the teachers' education since E-Learning is also gaining importance for school education and particularly for further education. It therefore seems to be desirable to have the teacher candidates work actively with E-Learning programs during professional education at universities.

Actually, our time is characterized by the emergence of new technologies and new subjects that enter school curricula. As a matter of fact, school teachers especially of secondary schools must teach increasingly subjects they have not been trained for. Furthermore, basic education as well as higher education represent an ever shorter part of the lifetime of a person. This situation poses new challenges to the individuals as well as the societies with respect to further education. One way to meet this challenge is E-Learning and this is another reason that teacher candidates should become familiar with ELearning during their university education. This task cannot be achieved theoretically, but must include practical exercises and learning. In other words, an ELearning course should be part of the professional training of teachers. This leads to the question which subject might be taught by means of E-Learning.

One of the subjects which presently undergo big changes is statistics (traditional stochastics) although it is not at all a "new" school subject. In Germany, as early as in 1901 probability calculus and combinatory became part of the curriculum of the secondary schools in Prussia because of the eminent importance of probability theory and statistics for natural sciences [3]. However, during the Nazi-time probability calculus was abandoned and after World War II also statistics were taken off from German school curricula. Only in the 1970s statistics (traditional stochastics) were gradually included into German school curricula with the target to promote and train "stochastic thinking". Unfortunately, the education of teacher candidates in statistics (traditional stochastics) is often restricted to one course, which gives a first brief overview on some selected statistical methods. These introductory courses generally omit a discussion of the fundamental issues like for instance the concept of probability, which is either introduced ambiguously or only as a mathematical entity. These educational shortcomings are frankly accepted, for example, Jäger and Schupp note "An explicit definition of the concept of probability can be omitted, if adequate perceptions about and founded methods for the handling of probabilities are developed.'[3]

To overcome these shortcomings in the statistics education of undergraduates, the German Federal Ministry of Education and Research (BMBF) has spent during the last decade a large amount of money and resources to support the development of E-Learning programs to enhance the quality of statistical education at German universities. However, as the questionnaire illustrates a majority of the students had no E-Learning experiences at all despite the fact that some large E-Learning projects were completed during the recent years like EMILeA-stat and New Statistics.

From this perspective, the Stochastikon experiment to develop Magister and offer it as an E-Learning alternative to the conventional course in statistics, seemed to be not very promising. However, in a relative short time it was accepted as a fully valid alternative to the conventional course. All participants in the questionnaire agreed that Magister is a learnable and usable educational tool. Even more surprising is the fact that more than $70 \%$ of the participants consider Magister with respect to the exam preparation as being superior to classroom teaching and 93.55\% would appreciate such E-Learning programs also for other subjects. The very positive opinion about Magister should therefore prompt to examine two questions:

(1) Which subjects of the curriculum of teacher candidates are adequate to be taught by e-learning systems?

(2) Should future e-learning systems be developed based on the virtual classroom as offered by Magister?

\section{APPENDIX: STOCHASTIKON MAGISTER QUESTIONNAIRE}

The online questionnaire started with stating its aim and the instruction that only one answer should be selected to each question. This mode of fill-out was chosen to get a more differentiated result that would reflect the individual preferences better. Below each question of the questionnaire (the original version is in German) is shown together with the possible choices. The results in percent of the choices are given on the left hand side.

Questions and the Choices:

\begin{tabular}{|c|c|c|}
\hline \multicolumn{2}{|c|}{$\begin{array}{l}\text { You can select only one answer for each question, which } \\
\text { should be the most appropriate one. }\end{array}$} & $\begin{array}{l}31: 46= \\
67.39 \%\end{array}$ \\
\hline $\begin{array}{l}\text { Q/A } \\
\text { No. }\end{array}$ & Question Content & $\begin{array}{l}\text { Answer } \\
\text { Rate }\end{array}$ \\
\hline $\begin{array}{c}\text { Questio } \\
\text { n 1: }\end{array}$ & $\begin{array}{l}\text { The main reason for not selecting statistics but } \\
\text { Stochastics for the oral examination is: }\end{array}$ & $100.00 \%$ \\
\hline 1 & $\begin{array}{l}\text { Stochastics is easier to understand and thus } \\
\text { easier to learn. }\end{array}$ & $0.00 \%$ \\
\hline 2 & Stochastics is more interesting. & $6.45 \%$ \\
\hline 3 & Stochastics is based on a unified approach. & $3.23 \%$ \\
\hline 4 & Stochastics is more realistic. & $16.13 \%$ \\
\hline 5 & $\begin{array}{l}\text { The Stochastics is a good preparation for } \\
\text { classroom teaching. }\end{array}$ & $9.68 \%$ \\
\hline 6 & $\begin{array}{l}\text { An E-Learning program is available for the } \\
\text { Stochastics, which is very useful for the exam } \\
\text { revision. }\end{array}$ & $6.45 \%$ \\
\hline 7 & $\begin{array}{l}\text { The Stochastics examination was recommended } \\
\text { by fellow students. }\end{array}$ & $51.61 \%$ \\
\hline 8 & I would recommend the Stochastic examination. & $6.45 \%$ \\
\hline 9 & $\begin{array}{l}\text { I would not recommend the Stochastic } \\
\text { examination. }\end{array}$ & $0.00 \%$ \\
\hline $\begin{array}{c}\text { Questio } \\
\text { n 2: }\end{array}$ & $\begin{array}{l}\text { How did you prepare for the exam in } \\
\text { Stochastics: }\end{array}$ & $100.00 \%$ \\
\hline 1 & $\begin{array}{l}\text { Preparing on-line according to the lessons and } \\
\text { modules of Magister in the CIP pool. }\end{array}$ & $0.00 \%$ \\
\hline 2 & $\begin{array}{l}\text { Preparing on-line according to the lessons and } \\
\text { modules of the Magister at home. }\end{array}$ & $35.48 \%$ \\
\hline 3 & $\begin{array}{l}\text { Preparing on the basis of the printed lessons } \\
\text { (content, exercises, and examples). }\end{array}$ & $51.61 \%$ \\
\hline 4 & Preparing on the basis of test protocols from & $3.23 \%$ \\
\hline
\end{tabular}




\section{Evaluate Stochastikon MaGister By QuestionnaIRE}

\begin{tabular}{|c|c|c|}
\hline & former test participants. & \\
\hline 5 & $\begin{array}{l}\text { Preparing in groups and with other test } \\
\text { participants. }\end{array}$ & $9.68 \%$ \\
\hline $\begin{array}{c}\text { Questio } \\
\text { n 3: }\end{array}$ & $\begin{array}{l}\text { Is the E-Learning system Magister a sufficient } \\
\text { basis to understand the examination material? }\end{array}$ & $96.77 \%$ \\
\hline \begin{tabular}{l|l}
1 \\
\end{tabular} & Yes, without restrictions. & $33.33 \%$ \\
\hline 2 & $\begin{array}{l}\text { Yes, but the content should be more detailed and } \\
\text { descriptive. }\end{array}$ & $0.00 \%$ \\
\hline 3 & $\begin{array}{l}\text { Yes, but there should be more examples and } \\
\text { exercises offered. }\end{array}$ & $33.33 \%$ \\
\hline 4 & $\begin{array}{l}\text { Yes, but only together with an introduction / a } \\
\text { preliminary meeting. }\end{array}$ & $33.33 \%$ \\
\hline 5 & $\begin{array}{l}\text { No, the offered support is insufficient even with } \\
\text { an introduction / preliminary meeting. }\end{array}$ & $0.00 \%$ \\
\hline $\begin{array}{c}\text { Questio } \\
\text { n 4: }\end{array}$ & $\begin{array}{l}\text { Questions for the exam in the subject } \\
\text { Stochastics: }\end{array}$ & $100.00 \%$ \\
\hline 1 & $\begin{array}{l}\text { Would the exam revision have been easier if } \\
\text { there would be a regular course in Stochastics } \\
\text { like in statistics? }\end{array}$ & $22.58 \%$ \\
\hline 2 & $\begin{array}{l}\text { The exam revision was easier than in other } \\
\text { subjects, because of the E-Learning system } \\
\text { Magister. }\end{array}$ & $45.16 \%$ \\
\hline 3 & $\begin{array}{l}\text { It would be good if also for other examination } \\
\text { subjects E-Learning systems such as the } \\
\text { Magister were available. }\end{array}$ & $25.81 \%$ \\
\hline 4 & $\begin{array}{l}\text { The E-Learning system Magister was no help } \\
\text { for the exam revision. }\end{array}$ & $6.45 \%$ \\
\hline \multirow[t]{2}{*}{$\begin{array}{c}\text { Questio } \\
\text { n 5: }\end{array}$} & Questions about E-Learning system Magister: & \\
\hline & $\begin{array}{l}\text { 5.1 How do you rate the ease of use of } \\
\text { Magister? }\end{array}$ & $100.00 \%$ \\
\hline 1 & Very good & $25.81 \%$ \\
\hline 2 & Good & $61.29 \%$ \\
\hline 3 & Satisfactory & $9.68 \%$ \\
\hline 4 & Sufficient & $3.23 \%$ \\
\hline \multirow[t]{3}{*}{5} & Poor & $0.00 \%$ \\
\hline & Average Score & 1.90 \\
\hline & $\begin{array}{l}5.2 \text { How do you rate the clarity of the lessons of } \\
\text { Magister? }\end{array}$ & $100.00 \%$ \\
\hline 1 & Very good & $12.90 \%$ \\
\hline 2 & Good & $74.19 \%$ \\
\hline 3 & Satisfactory & $12.90 \%$ \\
\hline 4 & Sufficient & $0.00 \%$ \\
\hline \multirow[t]{3}{*}{5} & Poor & $0.00 \%$ \\
\hline & Average Score & 2.00 \\
\hline & $\begin{array}{l}5.3 \text { How do you rate the response of the } \\
\text { Magister? }\end{array}$ & $96.77 \%$ \\
\hline 1 & Very good & $30.00 \%$ \\
\hline 2 & Good & $50.00 \%$ \\
\hline 3 & Satisfactory & $20.00 \%$ \\
\hline 4 & Sufficient & $0.00 \%$ \\
\hline \multirow[t]{3}{*}{5} & Poor & $0.00 \%$ \\
\hline & Average Score & 1.90 \\
\hline & $\begin{array}{l}5.4 \text { How do you rate the stability of the Magister } \\
\text { as a software program? }\end{array}$ & $96.77 \%$ \\
\hline 1 & Very good & $30.00 \%$ \\
\hline 2 & Good & $53.33 \%$ \\
\hline 3 & Satisfactory & $13.33 \%$ \\
\hline 4 & Sufficient & $3.33 \%$ \\
\hline
\end{tabular}

\begin{tabular}{|c|c|c|}
\hline 5 & Poor & $0.00 \%$ \\
\hline & Average Score & 1.90 \\
\hline & 5.5 How do you rate the layout of Magister? & $100.00 \%$ \\
\hline 1 & Very good & $12.90 \%$ \\
\hline 2 & Good & $54.84 \%$ \\
\hline 3 & Satisfactory & $29.03 \%$ \\
\hline 4 & Sufficient & $3.23 \%$ \\
\hline \multirow[t]{3}{*}{5} & Poor & $0.00 \%$ \\
\hline & Average Score & 2.23 \\
\hline & $\begin{array}{l}5.6 \text { How do you rate the working with the } \\
\text { Magister? }\end{array}$ & $100.00 \%$ \\
\hline 1 & Very satisfactory & $25.81 \%$ \\
\hline 2 & Adequate & $54.84 \%$ \\
\hline 3 & Neither satisfactory nor frustrating & $19.35 \%$ \\
\hline 4 & Frustrating & $0.00 \%$ \\
\hline \multirow[t]{3}{*}{5} & Very frustrating & $0.00 \%$ \\
\hline & Average Score & 1.94 \\
\hline & $\begin{array}{l}5.7 \text { Frequency of work with the Graphical } \\
\text { Laboratory }\end{array}$ & $96.77 \%$ \\
\hline 1 & Very often & $0.00 \%$ \\
\hline 2 & Less common & $16.67 \%$ \\
\hline 3 & Sometimes & $30.00 \%$ \\
\hline 4 & Rarely & $36.67 \%$ \\
\hline \multirow[t]{3}{*}{5} & Never & $16.67 \%$ \\
\hline & Average Score & 3.53 \\
\hline & $\begin{array}{l}5.8 \text { How do you rate the ease of use of the } \\
\text { Graphical Laboratory? }\end{array}$ & $90.32 \%$ \\
\hline 1 & Very good & $10.71 \%$ \\
\hline 2 & Well & $32.14 \%$ \\
\hline 3 & Satisfactory & $39.29 \%$ \\
\hline 4 & Sufficient & $17.86 \%$ \\
\hline \multirow[t]{2}{*}{5} & Poor & $0.00 \%$ \\
\hline & Average Score & 2.64 \\
\hline \multirow[t]{2}{*}{$\begin{array}{l}\text { Questio } \\
\text { n 6: }\end{array}$} & $\begin{array}{l}\text { Questions about the use of Magister and other } \\
\text { E-Learning systems in teaching. }\end{array}$ & \\
\hline & $\begin{array}{l}\text { 6.1 Which instruction statistics (with classroom } \\
\text { teaching) or Stochastics (with E-Learning } \\
\text { system) caused more understanding difficulties } \\
\text { to you? }\end{array}$ & $93.55 \%$ \\
\hline 1 & Statistics & $79.31 \%$ \\
\hline \multirow[t]{2}{*}{2} & Stochastics & $20.69 \%$ \\
\hline & $\begin{array}{l}\text { 6.2 In which of the two cases statistics } \\
\text { (classroom training) or Stochastics (E-Learning } \\
\text { system) the comprehension difficulties could be } \\
\text { overcome easier? }\end{array}$ & $93.55 \%$ \\
\hline 1 & Statistics & $17.24 \%$ \\
\hline \multirow[t]{2}{*}{2} & Stochastics & $82.76 \%$ \\
\hline & $\begin{array}{l}\text { 6.3 Have you experience with other E-Learning } \\
\text { systems besides Magister? }\end{array}$ & $100.00 \%$ \\
\hline 1 & yes & $25.81 \%$ \\
\hline \multirow[t]{2}{*}{2} & no & $74.19 \%$ \\
\hline & $\begin{array}{l}\text { 6.4 If yes, were the other E-Learning systems } \\
\text { offered as a support for classroom teaching or as } \\
\text { a substitute for classroom teaching? }\end{array}$ & $32.26 \%$ \\
\hline 1 & As a support & $70.00 \%$ \\
\hline \multirow[t]{2}{*}{2} & As a replacement & $30.00 \%$ \\
\hline & 6.5 Have you ever miss the classroom teaching & $100.00 \%$ \\
\hline
\end{tabular}




\begin{tabular}{|c|l|c|} 
& during the exam revision of Stochastics? & \\
\hline 1 & yes & $25.81 \%$ \\
\hline 2 & no & $74.19 \%$ \\
\hline & $\begin{array}{l}\text { 6.6 Could you imagine based on your learning } \\
\text { experience with Magister, that other parts of } \\
\text { mathematics and natural science could also be } \\
\text { taught successfully by using an E-Learning } \\
\text { system without classroom teaching (possibly } \\
\text { with some few attendance meetings, similar to } \\
\text { the introduction in Stochastics and Magister by } \\
\text { Professor von Collani)? }\end{array}$ & $100.00 \%$ \\
\hline 1 & yes & $93.55 \%$ \\
\hline 2 & no & $6.45 \%$ \\
\hline & & $\begin{array}{l}\text { 6.7 Which branches of mathematics may be } \\
\text { considered? }\end{array}$ \\
\hline 1 & Analysis & $96.77 \%$ \\
\hline 2 & Linear Algebra & $0.00 \%$ \\
\hline 3 & Numerical Analysis & $10.00 \%$ \\
\hline 4 & Geometry & $6.67 \%$ \\
\hline 5 & Algebra & $20.00 \%$ \\
\hline 6 & Measure Theory & $16.67 \%$ \\
\hline 7 & Probability & $0.00 \%$ \\
\hline 8 & Experimental Physics & $33.33 \%$ \\
\hline 9 & Theoretical Physics & $13.33 \%$ \\
\hline & & \\
\hline & & \\
\hline & & \\
\hline & & \\
\hline & & \\
\hline & & \\
\hline & & \\
\hline
\end{tabular}

\section{REFERENCES}

[1] H. Dichanz, and A. Enst, „E-Learning - Begriffiche, psychologische und didaktische Überlegungen zum "electronic learning”". MedienPädagogik - Online-Zeitschrift für Theorie und Praxis der Medienbildung, Virtualität und E-Learning, $\mathrm{H}$. Dichanz, Ed., 2001.

[2] ISO, "Guidance on Usability", Draft International ISO DIS 9241 11 Standard, Nigel Bevan, Ed. September 1994.
[3] J. Jäger and H. Schupp, „Curriculum Stochastik in der Hauptschule“, Erdinand Schöningh, Paderborn, pp. 16, pp19, 1983.

[4] J. Symanzik and N. Vukasinovic, "Teaching Statistics with Electronic Textbooks" in COMPSTAT, Proceedings in Computational Statistics, W. Härdle and B. Rönz, Eds. Heidelberg: Physica-Verlag, 2002, pp. 79-90.

[5] J. Symanzik and N. Vukasinovic, "Comparative Review of ActivStats, CyberStats, and MM*Stat," MSOR Connections, vol. 3, no. 1, pp. 37-42, 2003.

[6] X. Zhai, "Two Old Statistical Methods in a New Stochastic Outfit”, Economic Quality Control, vol. 23, no. 1, pp. 29-38, 2008. doi:10.1515/EQC.2008.29

[7] X. Zhai and E. von Collani, "Strategies for Teaching a Novel Approach to Handling Uncertainty Scientifically via Internet" International Journal of Emerging Technologies in Learning (iJET), vol. 4, no 2, pp. 52-57, 2009.

[8] X. Zhai and E. von Collani, "A Graphical Tool for Visualizing Bernoulli Stochastics", International Journal of Emerging Technologies in Learning (iJET), vol. 4, no 3, pp. 44-50, 2009.

[9] X. Zhai, "Uncertainty and E-Learning", Economic Quality Control, vol. 24, no. 2, pp. 157 - 177, 2009. doi:10.1515/EQC. $\underline{2009.157}$

[10] X. Zhai, "Empirical Evaluation of Stochastikon Magister" Economic Quality Control, vol. 25, no. 2, pp. (appear soon), 2010.

\section{AUTHOR}

X. Zhai has a Ph.D. in System Engineering in China and is presently a doctoral student of the Faculty of Mathematics and Computer Science, Würzburg University, Schießhausstraße 15, D-97072 Würzburg, Germany. (e-mail: zhaixiaomin@ hotmail.com).

Dr. E. von Collani is a Professor at the Faculty of Mathematics and Computer Science, Würzburg University, Schießhausstraße 15, D-97072 Würzburg, Germany. (e-mail: elartvoncollani@yahoo.com).

Submitted October $28^{\text {th }}$, 2010. Published as resubmitted by the authors March $1^{\text {st }}, 2011$. 